\title{
NEMATOSES DE ALTA IMPORTÂNCIA ECONÔMICA DA CULTURA DO MELÃO NO ESTADO DO RIO GRANDE DO NORTE, BRASIL
}

\author{
ROMERO M. DE MOURA ${ }^{1}$, ELVIRA M. R. PEDROSA ${ }^{2}$ \& LÍLIAN M. P. GUIMARÃES ${ }^{1}$
}

\begin{abstract}
${ }^{1}$ Departamento de Agronomia, ${ }^{2}$ Departamento de Tecnologia de Rural, Universidade Federal Rural de Pernambuco, Dois Irmãos, 52171-900, Recife, PE; e-mail: romero@yahoo.com.br
\end{abstract}

(Aceito para publicação em 26/11/2001)

Autor para correspôndencia: Romero M. de Moura

\section{ABSTRACT \\ Nematode problems of the melon crop in the State of Rio Grande do Norte, Brazil}

This paper reports the occurrence of the nematodes Rotylenchulus reniformis, Meloidogyne javanica and M. incognita in melon (Cucumis melo) fields of the Tropical Fruit Project Mossoró-Açu,
Rio Grande do Norte, Brazil. The presence of the these nematodes was associated with large patchy growth and severe yield losses. This is the first report of $R$. reniformis infecting melon in Brazil
O Laboratório de Fitonematologia da Universidade Federal Rural de Pernambuco foi solicitado pela Associação dos Produtores e Exportadores de Frutas Tropicais do Nordeste (Pró-Frutas), para efetuar visita fitossanitária em propriedades produtoras de melão, localizadas nos municípios de Mossoró e Açu, região oeste do Estado, que apresentavam áreas com reduções crescentes em produtividade. $\mathrm{O}$ fenômeno ocorria em plantios de meloeiro do tipo amarelo, causado por doença de etiologia desconhecida pela maioria dos agricultores. Constataramse grandes reboleiras (Figura 1) onde existiam falhas de germinação, plantas com amarelecimento discreto e forte nanismo, mostrando-se a cultivar Gold Mine altamente suscetível. Frutos colhidos em áreas contaminadas eram de dimensões e características gerais inferiores, não servindo para comercialização. Examinando-se plantas afetadas dentro das reboleiras, caracterizaram-se dois tipos de síndrome. No primeiro, os sistemas radiculares mostravamse atrofiados, com muitas galhas, expondo massas de ovos; sintomas e sinais típicos de meloidoginose. Em plantas de mais de 30 dias, as galhas, ao serem dissecadas, mostravamse habitadas por fêmeas pertencentes a uma das espécies do nematóide das galhas; Melodogyne javanica (Treub) Chitwood e M. incognita (Kofoid \& White) Chitwood, identificadas pelo método de Taylor, A.L. \& Sasser, J.N. (Biology Identification and Control of Root-Knot Nematodes. IMP., NCSU, 1978). Houve predominância da primeira espécie nas amostras e em apenas poucos casos foram diagnosticadas áreas infestadas por populações mistas. Análises de densidade populacional, usando-se o método de extração segundo Jenkins, W.R. (Pl. Dis. Rep. 48:692, 1964), revelaram níveis considerados altos, superiores, em alguns casos, a 5.000 juvenis/100 cc de solo de reboleira. $\mathrm{Na}$ segunda síndrome, os sintomas gerais de campo eram semelhantes, mas as plantas não apresentavam galhas e sim necroses localizadas. O exame microscópico de raízes em plantas de mais de 30 dias, após submetidas a processo de coloração, mostrou a presença de fêmeas maduras do nematóide ectoparasito sedentário Rotylenchulus reniformis Linford \& Oliveira, identificado segundo Dasgupta et al. (Proc. Hel. Soc. Was. 35:169-192, 1968). No solo, usandose o mesmo método de extração, foram detectadas densidades populacionais de $R$. reniformis muito altas, com níveis superiores a 15.000 espécimes (machos, fêmeas adultas imaturas e juvenis) por $100 \mathrm{cc}$ de solo. A meloidoginose do meloeiro teve o primeiro assinalamento no Brasil feito por Mello, L. M. (Revista de Agricultura, Piracicaba, SP., 33:39$44,1958)$ e o relato da importância econômica em Açu, RN, por D. Tihohod et al. (XVIII Congresso Brasileiro de Nematologia, Resumos, Jaboticabal, 92, 1993). Este é o primeiro registro de $R$. reniformis em meloeiro no Brasil.

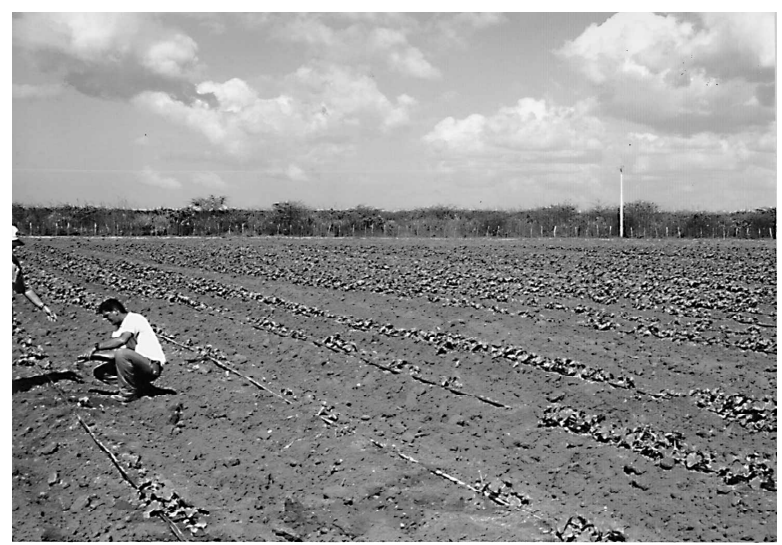

FIG. 1 - Reboleira em área de meloeiro (Cucumis melo) causada por fitonematóides no Estado do Rio Grande do Norte. 